Int. J. Dev. Biol. 57: 897-906 (2013)

doi: $10.1387 / \mathrm{ijdb} .130077 \mathrm{sg}$

\title{
Identification and characterization of VEGF and FGF from Hydra
}

\author{
LAKSHMI-SUREKHA KRISHNAPATI and SURENDRA GHASKADBI* \\ Division of Animal Sciences, Agharkar Research Institute, Pune, India
}

\begin{abstract}
Vascular endothelial growth factor (VEGF) and fibroblast growth factor (FGF) play important roles in the formation of the blood vascular system and in axon guidance, nervous system development and function. Here, we report isolation and characterization of VEGF and FGF homologues from Hydra vulgaris Ind-Pune, a Cnidarian which exhibits an organized nervous system and primitive epithelio-muscular cells. VEGF expression was prominent in the endoderm of the peduncle region and tentacles, as evident from in situ hybridization of whole polyps and its transverse sections. High levels of FGF were detected in the ectoderm of the budding region. The expression of VEGF in endodermal and $F G F$ in interstitial cells was confirmed using sf-1 hydra, a temperature-sensitive mutant strain of Hydra magnipapillata. Tissue-specific expression of VEGF and FGF was confirmed by semi quantitative RT-PCR for ectodermal and endodermal tissues in $H$. vulgaris Ind-Pune. Treatment with SU5416, a specific inhibitor of the VEGF receptor, did not affect the whole polyp, but did delay both budding and head regeneration, suggesting a possible role of VEGF in nerve cell development, tube formation and/or in branching. FGF expression in the ectoderm of budding region, where the majority of interstitial stem cells reside suggests its role in interstitial stem cell maintenance. Further, activation of canonical Wnt signalling with the glycogen synthase kinase-3 $\beta$ (GSK-3 $\beta$ ) inhibitor alsterpaullone caused down-regulation of VEGF and FGF, suggesting an antagonistic relationship between the Wnt and VEGF/FGF pathways. Our results indicate that VEGF and FGF evolved early in evolution, before the development of the blood vascular system, and open up the possibility of elucidating the evolutionarily ancient functions of VEGF and FGF.
\end{abstract}

KEY WORDS: Evolution, FGF, hydra, nervous system, VEGF

\section{Introduction}

Nervous and vascular systems perform specialized functions in higher metazoans to meet the need for efficient information and nutrient transfer, respectively. In simple invertebrates, these processes are governed by simple structures such as a primitive nerve network and a gastro vascular system. Recent evidence suggests that several guidance cues including signalling molecules like vascular endothelial growth factor (VEGF) and fibroblast growth factor (FGF) are common to both these systems. VEGF, the most potent angiogenic factor, was originally discovered as an endothelial specific growth factor. However, VEGF was shown to be secreted by non-endothelial cells such as astrocytes, nerve cells, neural stem cells (NSCs) and Schwann cells (reviewed in Ruiz de Almodovar et al., 2009). A recent report demonstrates that VEGFA and Cxcl12 (stromal cell-derived factor-1), secreted by nerves, control arterial differentiation and the pattern of vascular branching resulting in nerve-artery alignment (Li et al., 2013). VEGF also stimulates proliferation and survival of NSCs, and its role in neuronal growth is confirmed by its neuroprotective and neurotrophic effects on neural and glial cells in vitro as well as in vivo pointing towards its involvement in functions other than blood vascular development (Jin et al., 2002).

Novel functions of FGFs, similarly, in processes other than angiogenesis have emerged. While being a proangiogenic molecule, FGF-2 also plays a key role during neural development. We have shown that FGF signalling modulates expression of ERNI (Early Response to Neural Induction), noggin, goosecoid and brachyury indicating the importance of FGF in neural induction and specification of notochord (Khot and Ghaskadbi 2001; Borgave and Ghaskadbi

Abbreviations used in this paper: DMSO, Dimethylsulfoxide; FGF, fibroblast growth factor; GSK, glycogen synthase kinase; sf-1, self-feeder-1; VEGF, vascular endothelial growth factor; Wnt, wingless/integrated.

\footnotetext{
*Address correspondence to: Surendra Ghaskadbi. Animal Sciences Division, Agharkar Research Institute, G.G. Agarkar Road, Pune-411 004, India. Tel: +91-20-2567-3959. Fax: +91-20-2565-1542. E-mail: ghaskadbi@gmail.com - web: http://www.aripune.org/bio-smg.asp
} 
2009). Though, role of FGFs in angiogenesis is known, their precise function(s) in neuroprotection, synapseformation and axon guidance are still not clear. Accumulating evidence thus indicates existence of regulatory links between vascular and nervous systems at the molecular level.

While vertebrate models are useful for studying molecular signalling, simple model organisms belonging to invertebrate phyla have led to the identification of evolutionary functions of several molecules. Recent findings on the presence of VEGF, FGF and their receptors in simple and evolutionarily ancient invertebrates, which are devoid of blood vascular system, suggest that these invertebrate models could help us in identifying the significance of interacting signalling pathways participating in patterning of various systems. VEGF and its receptor, VEGFR have been shown to participate in processes leading to tube formation in Podocoryne carnea, a member of phylum Cnidaria (Seipel et al., 2004). Similarly, FGF and FGFR homologues have been identified in Nematostella vectensis,

A \begin{tabular}{ll|} 
HUVEGFC & 300 \\
HuVEGFD & 254 \\
Chironomus & 1302 \\
P. carnea & 260 \\
Hydra & 187
\end{tabular}

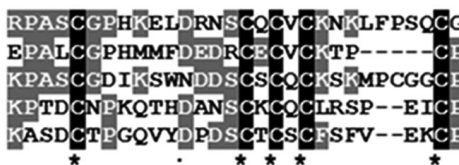
CGANREFDENTC
CPKDLIQHPKNC
CPPNQQWNEKTC
CPISKE WSNEMC
CPVGKQWSIVNC

B H. sapiens H. sapiens VEGFC H. sapiens VEGFD M. musculus G. gallus $X$. laevis D. rerio Aa D. rerio $\mathrm{Ab}$ D. melanogaster PVF C. elegans PVF1 P. carnea Hydra

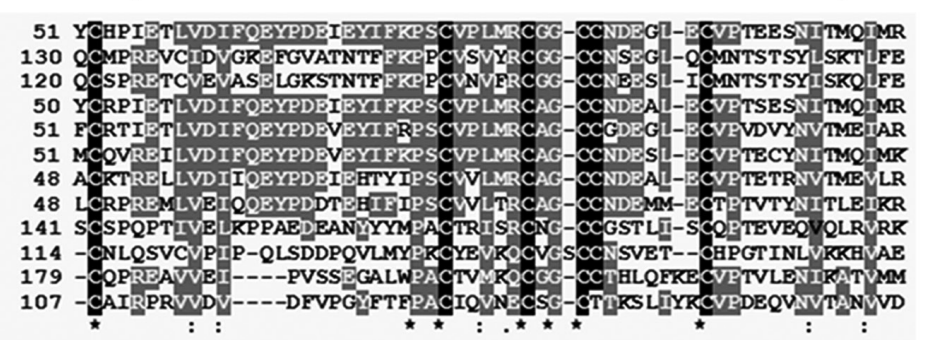

D. melanogaster PVF1 H. sapiens M. musculus G. gallus $X$. laevis D. rerio Aa D. rerio $\mathrm{Ab}$ H. sapiens VEGFC H. sapiens VEGFD P. carnea Bydra C. elegans PVF1

C H. sapiens M. musculus G. gallus G. Iaevis D. rerio N. vectensis FGFA1 N. vectensis FGF1B Hydra
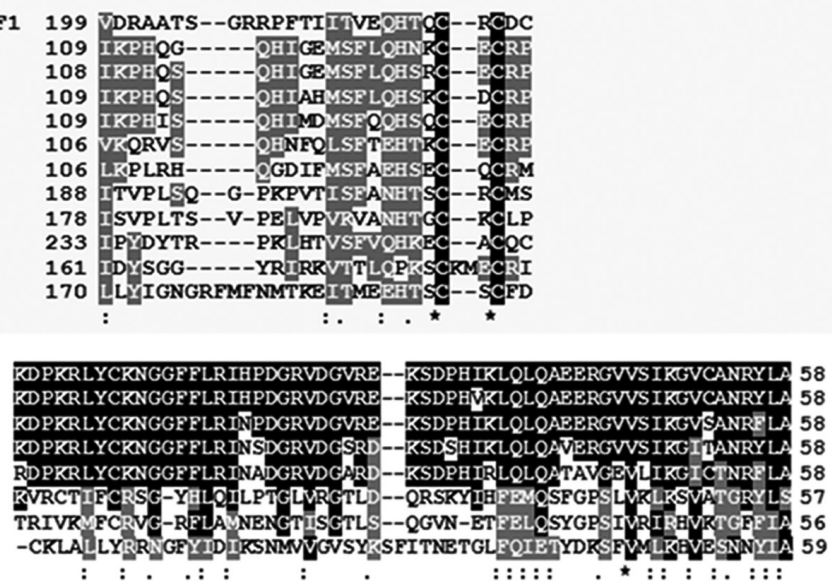

H. sapiens

M. musculus

G. gallus

$X$. Iaevis

D. rerio

N. vectensis FGFA1 $N$. vectensis FGF1B Hydra

H. sapiens

M. musculus

G. gallus

X. laevis

D. rerio

N. vectensis FGFA1 N. vectensis FGF1B Bydra

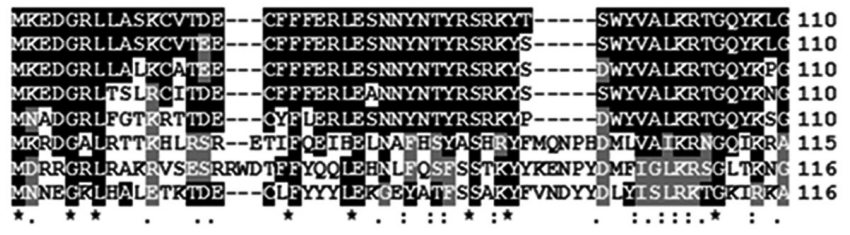

SKTGPGQRAILFLEMS 126 SRTGPGQRAILFLPMS 126 PKTTEGQKAILFLEMS 126 SSTGPGQRAILFLPMS 126 SKTSPGQRAILFLEMS 126 TKTTREGTATQFLVIR 131 NHSTEFRSSQFEIIIP 132

an anthozoan Cnidarian, which carry out important functions in gastrulation, neural induction and formation of apical sensory organ (Matus et al., 2007). Though VEGF and FGF pathways were found to be evolved much before bilaterian evolution, functional roles of VEGF and FGF in lower metazoans are not clear.

The present work was undertaken to find out if VEGF and FGF are present in hydra, a representative of phylum Cnidaria, which is the most primitive phylogenetic group possessing an organized nervous system in the form of a nerve net. Hydra has been a favourite model organism because of its remarkable regeneration capacity, true tissue grade organization, simple body architecture and fewer types of cells (reviewed in Bode 1996). Homologues of numerous genes that participate in various developmental processes have been identified in hydra (Chandramore et al., 2010; Hemmrich et al., 2012). Molecular studies have revealed the identification of a signal peptide-containing sequence corresponding to VEGF by cDNA screening in Hydra vulgaris (Böttger et al. , 2006). Similarly, characterization of FGFR (kringelchen) from hydra shows that it participates in bud detachment (Sudhop et al., 2004). These findings strongly suggest the possible presence of VEGF and FGF in hydra. Here, we have analyzed the structure and expression of VEGF and FGF in Hydra vulgaris Ind-Pune, a distinct strain of the vulgaris species, particular to the type locality, Pune, India (Reddy et al., 2011). We find that hydra VEGF and FGF are structurally conserved and are predominantly expressed in endodermal and ectodermal cells, respectively. Aspects of gene structures, expression patterns and the association between Wnt and VEGF/FGF signalling pathways are studied. Understanding the basal functions of VEGF and FGF in hydra would help us in identifying their evolutionary functions.

\section{Results}

\section{Isolation of VEGF and FGF homologues in hydra}

Putative gene models for VEGF and FGF were identified from $H$. magnipapillata genome browser corresponding to genomic Contigs 33132:25806.32241 and 37378:93839.104729, respectively. BLAST and SMART analyses of

Fig. 1. Structural conservation of VEGF and FGF in hydra. Sequence alignment of the conserved cysteine

rich motifs, CXCXC at the C-terminus of VEGF in Hydra,

P. carnea, Human (Hu) VEGFC, VEGFD and $185 \mathrm{kDa}$ protein of Chironomous pallidivittatus showed
considerable conservation (A). Alignment of VEGF/PDGF homology domain (VHD) across phyla from hydra to vertebrates showing functionally conserved cysteine residues (B). The highly conserved cysteine residues are highlighted in black while other conserved amino acids are in grey. Clustal W analysis of hydra FGF domain with other FGF homologues showed conservation of FGF domain across phyla (C). The conserved residues are highlighted in black and similar amino acids are shown in grey. 
predicted amino acid sequences for VEGF and FGF revealed conservation of corresponding PDGF and FGF domains. The complete coding sequence (CDS) of hydra VEGF (807 bp) and partial CDS of FGF (622 bp) were cloned from Hydra vulgaris Ind-Pune using total RNA as template for cDNA synthesis, followed by PCR. The clones were sequenced and submitted to the Genbank with accession nos FJ767839 and JF803424 for VEGFand FGF, respectively.

\section{Structural conservation of VEGF and FGF}

In silico analysis of VEGF gene product of 269 amino acid residues revealed the presence of a 20 amino acid residue secretory signal sequence at the $\mathrm{N}$-terminus. Sequence comparison by Clustal $\mathrm{W}$ analysis showed conservation of several repeats of cysteine-rich motifs towards C-terminus (Fig. 1A) and VEGF/ PDGF homology domain (VHD) (Fig. 1B) as observed in P. carnea
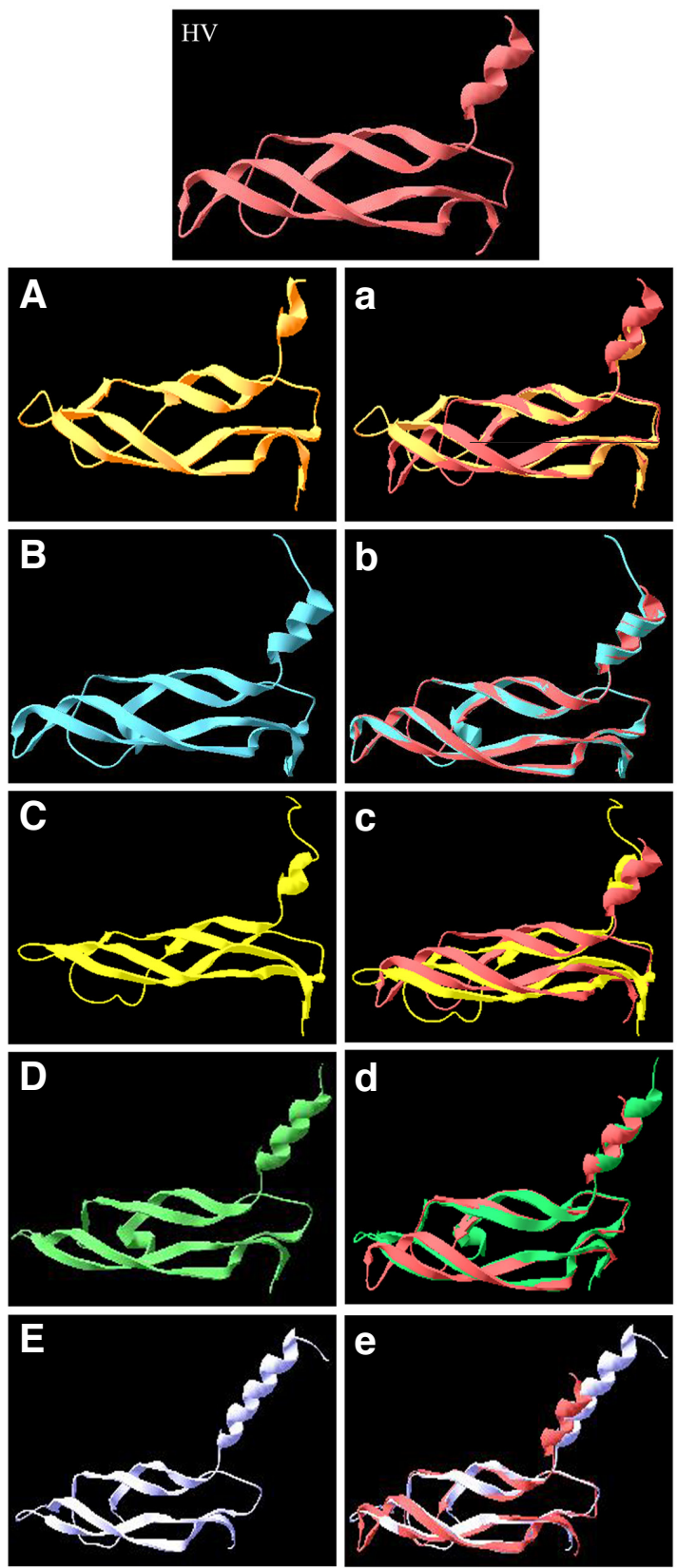
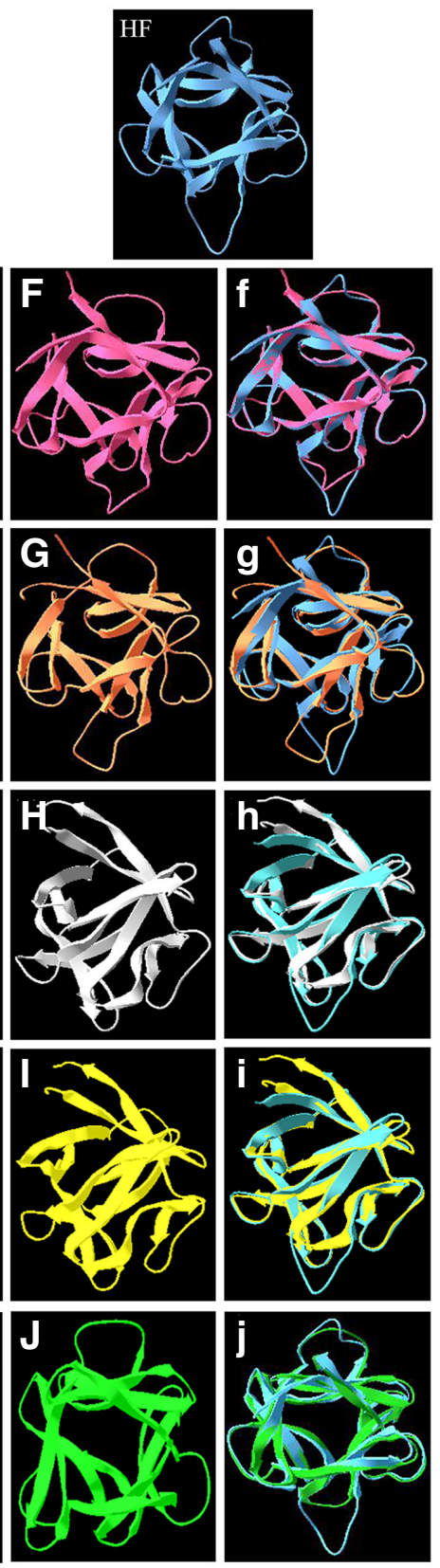

VEGF, $185 \mathrm{kDa}$ giant silk protein of Chironomus pallidivittatus and human VEGF-C and -D (Seipel et al., 2004). Similarly, hydra FGF domain when compared to FGF domains in other FGF homologues exhibited high similarity with Nematostella vectensis FGF1B and N. vectensis FGFA1 (Fig. 1C). Further, presence of Glycine box, an amino acid motif (RKTGKIRKANHSTPFQR) comprising basic amino acids that help in binding heparan sulfate proteoglycans (HSPGs) (Ashikari-Hada et al., 2004) is also present in hydra FGF. Presence of highly conserved cysteine residues at the $\mathrm{C}$-terminus and conserved VHD in hydra VEGF and presence of FGF domain and Glycine box in hydra FGF suggests structural conservation of VEGF and FGF from hydra to vertebrates.

\section{Homology modelling and phylogenetic analysis}

VEGFs and FGFs have been found in all vertebrate species examined till date and the sequence and genomic organization are highly conserved across species (reviewed in Itoh and Ornitz 2004; reviewed in Holmes and Zachary 2005). Hydra VEGF and FGF were therefore compared to their homologues and homology based protein models were generated using DeepView Swiss-PdbViewer (SPDBV) to study the degree of structural resemblance between them (Fig. 2). Our analysis indicated that structurally, hydra VEGF domain architecture (Fig. 2HV) is more closely related to Orf virus VEGFE (Fig. 2B). Lowest root mean square deviation (RMSD) value was observed when hydra VEGF structure was superimposed

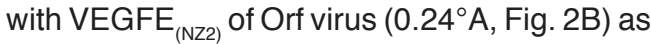
compared to $P$. carnea VEGF $\left(1.04^{\circ} \mathrm{A}\right.$, Fig. $\left.2 \mathrm{~A}\right)$, Homo sapiens VEGFB (1.04, Fig. 2C), VEGFC $\left(1.09^{\circ} \mathrm{A}\right.$, Fig. 2D) and VEGFD (1.14 ${ }^{\circ} \mathrm{A}$, Fig. $\left.2 \mathrm{E}\right)$ indicating close resemblance of hydra VEGF topology to VEGFE. Homology based protein models generated for hydra FGF (Fig. 2HF) showed close resemblance with Nematostella vectensis FGF1B (Fig. 2F). Superimposition of hydra FGF (Fig. 2HF) with $N$. vectensis FGF1B, FGFA1, Xenopus laevis, Mus musculus and $H$. sapiens FGF-2 (Fig. 2 F-J) showed RMSD values of $0.26^{\circ} \mathrm{A}, 1.07^{\circ} \mathrm{A}, 0.74^{\circ} \mathrm{A}, 0.75^{\circ} \mathrm{A}$ and $0.73^{\circ} \mathrm{A}$ respectively, suggesting close resemblance of hydra FGF with $N$. vectensis FGF1B. Further, phylogenetic analyses using neighbour joining

Fig. 2. Analysis of molecular models of VEGF (A-F) and FGF (G-L) protein structures. Comparison of hydra VEGF (HV) with P. carnea (A), Orf virus VEGFE (B) H. sapiens VEGFB (C), VEGFC (D), and VEGFD (E) showed close resemblance to Orf virus VEGFE after superimposition (b). Hydra FGF(HF) when compared to $\mathrm{N}$. vectensis FGF1B (F), N. vectensis FGFA1 (G), X. laevis (H), M. musculus (I), H. sapiens (J) FGF-2 structures showed close resemblance to $\mathrm{N}$. vectensis FGF1B(F). Superimposed structures ofVEGFmembers with hydra VEGF were shown from a-e while FGF superimposed structures were shown from $f$-j. The protein structures were generated using Swiss Model program based on homology modelling. 
(NJ), maximum parsimony (MP) and maximum likelihood (ML) methods revealed that hydra VEGF and FGF cluster with $P$. carnea VEGF (Fig. 3A) and N. vectensis FGF1B (Fig. 3B) respectively, suggesting their close resemblance to Cnidarian counterparts.

\section{Localization of VEGF and FGF}

Whole mount in situ hybridization using either DIG- or biotinlabeled riboprobes was carried out followed by serial transverse sectioning of the specimens to study germ line-specific localization of VEGF and FGF in hydra. VEGF transcripts were found to be localized to the endodermal layer of peduncle region (basal $1 / 3^{\text {rd }}$ region) with relatively low levels in the endoderm of upper body column and tentacles as seen by whole mount in situ hybridization (Fig 4B) and in transverse sections (Fig.4 G-I). This suggests the

A

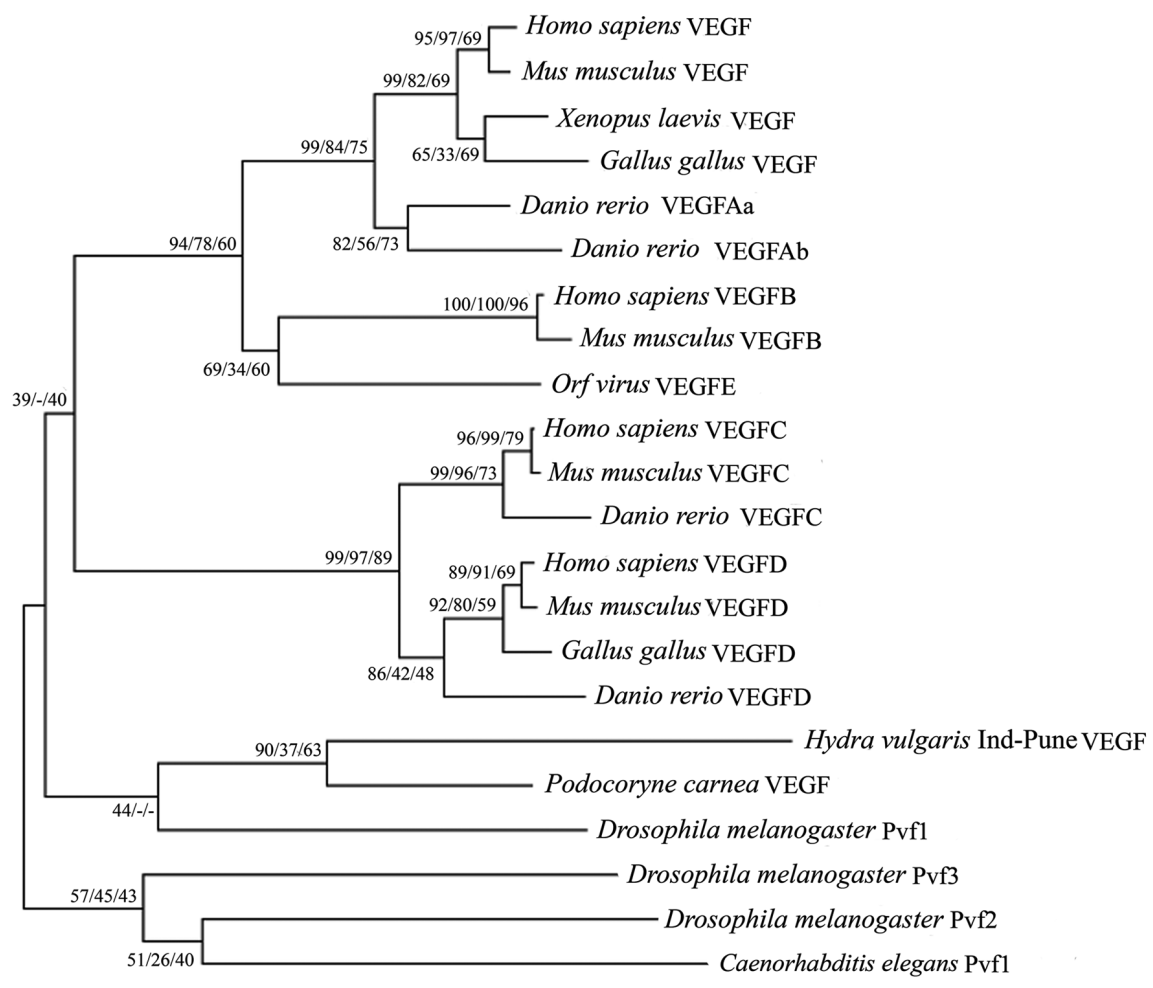

B

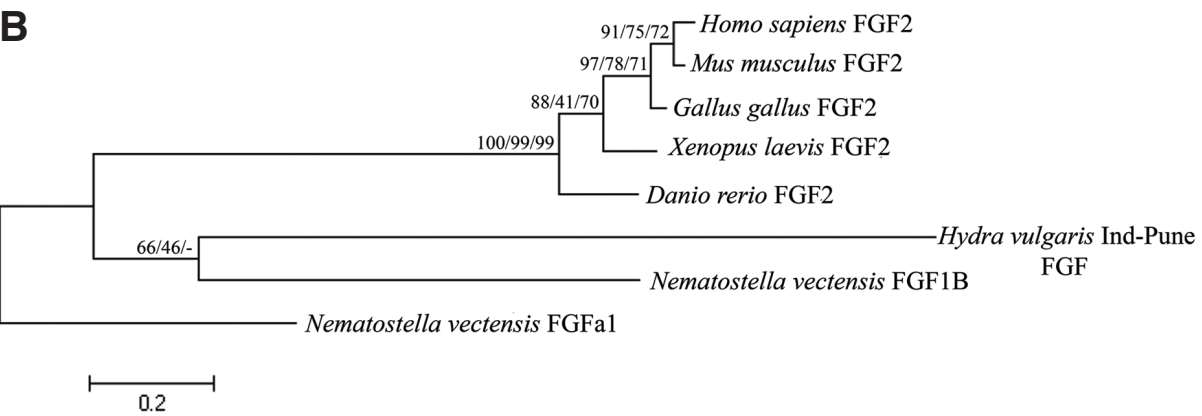

Fig. 3. Phylogenetic trees computed for VEGF (A) and FGF (B). The trees were inferred by Neighbour-Joining (NJ) method in MEGA5. Bootstrap values indicated at the branch points are inferred from NJ, ML and MP methods (left to right). The bootstrap consensus tree was inferred from 1000 replicates to represent the evolutionary history of the taxa analyzed. Scale bar indicates amino acid substitutions per site. presence of VEGF either in asymmetrical bipolar neurons, which are endodermal in origin or in the endodermal epithelial cells or both. Though FGF was observed in both the layers of body column, higher levels of FGF transcripts were detected in the ectoderm of budding region and the expression was found to be reduced towards both extremities (Fig. 4D, K-M). Since interstitial stem cells are located mainly in the budding region and differentiated cells are present towards the extremities, the expression of FGF in the ectoderm of budding region suggests its possible presence in I-cells.

\section{Expression analysis of VEGF and FGF in sf-1 hydra}

I-cells are lost rapidly in sf- 1 strain, a temperature sensitive variant of $H$. magnipapillata, when the polyps are maintained at a restrictive temperature of $28^{\circ} \mathrm{C}$ for $4-5$ days (Terada et al., 1988). sf -1 hydra maintained at $18^{\circ} \mathrm{C}$ were used as controls. The expression levels of VEGF and $F G F$ were studied in sf-1 hydra kept at $18^{\circ} \mathrm{C}$ and $28^{\circ} \mathrm{C}$, by semi quantitative RTPCR. Cnnos 1, the nanos homolog in hydra was used as a positive control. Cnnos 1 is expressed only in the multipotent stem cells and germline cells (Mochizuki et al., 2000). RT-PCR data showed up-regulation of VEGF transcripts, whereas the expression of $F G F$ was down-regulated in hydra kept at $28^{\circ} \mathrm{C}$ as compared to controls (Fig. 5). The loss of multipotent stem cells in hydra maintained at $28^{\circ} \mathrm{C}$ was evident from the decreased expression of Cnnos1 transcripts. Concomitant reduction in the number of FGF transcripts in sf- 1 hydra kept at $28^{\circ} \mathrm{C}$ points towards the expression of FGF in interstitial stem cells.

\section{Tissue specific expression of VEGF and FGF}

From whole mount in situ hybridization data and expression studies in sf-1 strain, it appeared that VEGFis largely expressed in endoderm and FGF in ectoderm. To confirm the tissue specific expression of VEGF and FGF in hydra, separated ectoderm and endoderm were analyzed by semi quantitative RT-PCR. To confirm clean separation of ectoderm and endoderm, Hy042/nb042, localized distinctly in the differentiating nematocytes of ectoderm and Dlp1/HyDkk1/2/4-C, expressed specifically in the gland cells of endoderm were used as ectoderm-and endoderm-specific markers, respectively (Lange et al., 2011). RT-PCR results showed amplification of VEGF only in the endodermal tissue confirming its expression only in endodermal cells while FGFexpression was largely in the ectoderm (Fig. 6). These results confirm the in situ hybridization analysis in wild type hydra and expression studies in sf-1 hydra. 

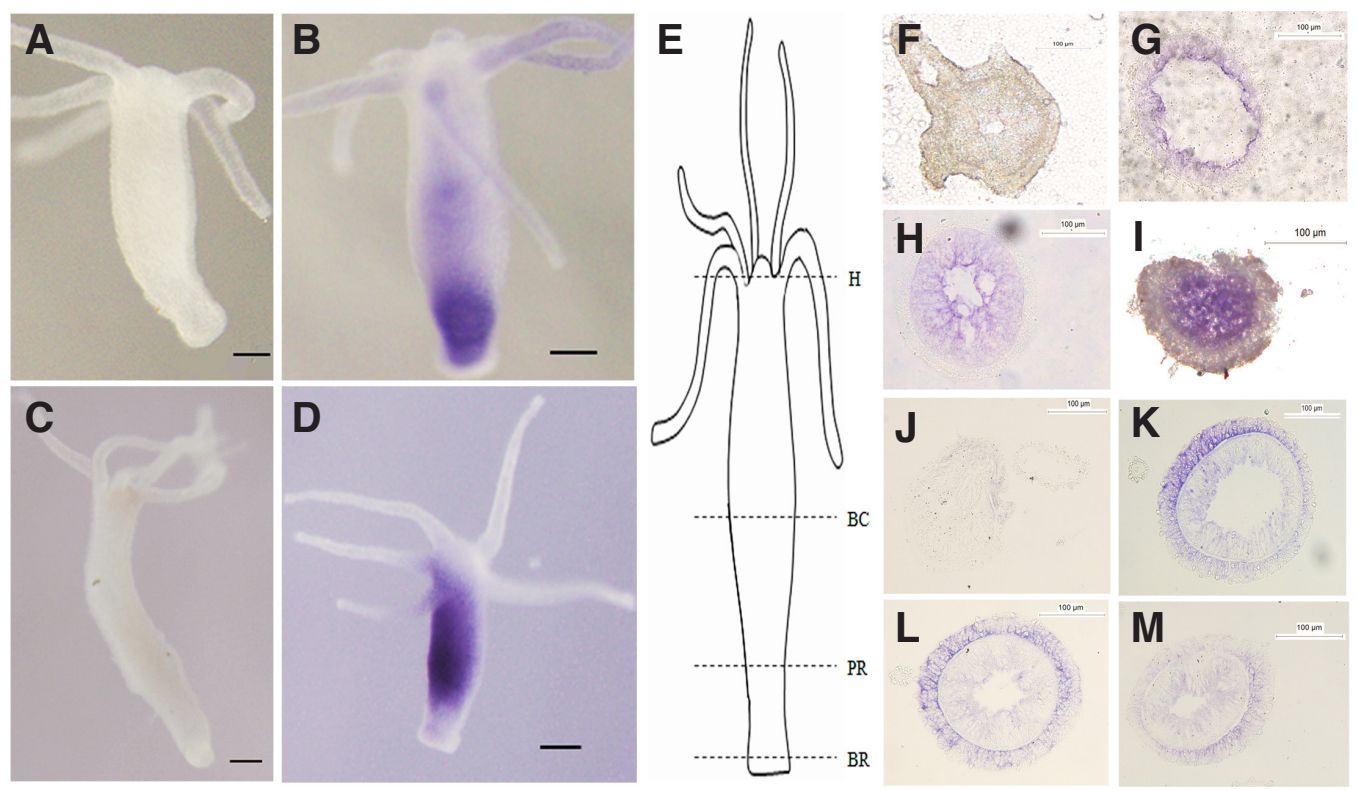

Fig. 4. Localization of VEGF and FGF in hydra by whole mount in situ hybridization. Whole mount in situ hybridization with DIG-labeled VEGF anti sense riboprobes (B) shows expression in the endoderm of peduncle $\left(1 / 3^{\text {rd }}\right.$ basal region), upper body column and tentacles. FGF expression is largely localized in the ectoderm of budding region and endoderm of tentacles (D). (A,C) Hybridization with corresponding sense probes, for VEGF and FGF. Schematic representation of hydra showing levels of sections passing through hypostome $(H)$, body column $(B C)$, Peduncle region (PR) and basal region (BR) (E). Transverse sections post in situ hybridization shows VEGF localization in the endoderm of body column (G), peduncle region $\mathbf{( H )}$ and basal region (I) with clean ectoderm. Localization of FGF transcripts is observed in both ectoderm and endoderm layers of body column (K), peduncle region (L) and basal region (M). Clean hypostome indicates the absence of VEGF and FGF expression (F,J). Scale bar, $100 \mu \mathrm{m}$.

\section{Activation of canonical Wnt pathway causes down-regulation of VEGF and FGF}

Inactivation of glycogen synthase kinase-3 $\beta$ (GSK3 $\beta$ ) leads to accumulation of $\beta$-catenin in the nucleus in the presence of activated Wnt signalling pathway causing regulation of gene expression. To determine if activated Wnt signalling affects VEGF and/ or FGF signalling, we used alsterpaullone to block GSK3 $\beta$ that activates the canonical Wnt pathway in hydra. Treatment with $5 \mu \mathrm{M}$ alsterpaullone for $24 \mathrm{~h}$ followed by return to hydra medium for $48 \mathrm{~h}$ resulted in the formation of ectopic tentacles along the upper $2 / 3^{\text {rd }}$ portion of the body column demonstrating over-activation of Wnt signalling pathway (Fig. 7A). Semi quantitative RT-PCR analysis of the expression levels of VEGF and FGF was carried out after 4, 24 and $48 \mathrm{~h}$ (Fig. 7 B-D) following transfer to fresh medium. Significant down-regulation of both genes was observed after 24
A

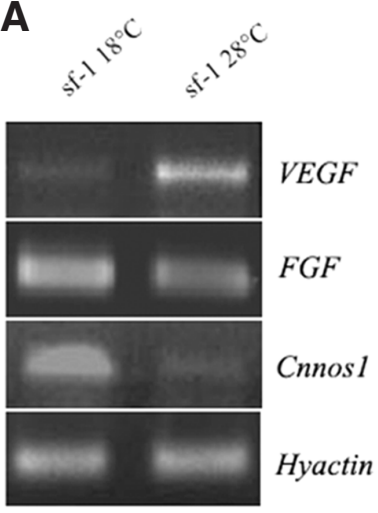

B

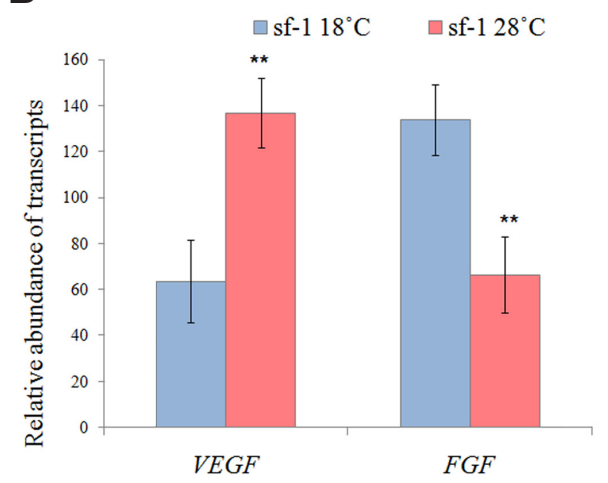

Fig. 5. Expression analysis of VEGF and FGF in sf-1 hydra. (A) RT-PCR results show significant up-regulation of VEGF and down-regulation of FGF in sf-1 hydra. The loss of multipotent stem cells is evident from decreased expression of Cnnos1. (B) Histogram represents relative abundance of transcripts of VEGF, FGF and Cnnos1 in sf-1 hydra maintained at $18^{\circ} \mathrm{C}$ and $28^{\circ} \mathrm{C}$. ${ }^{*}$ shows corresponding statistical significance, $p<0.001$. and $48 \mathrm{~h}$ (Fig. $7 \mathrm{C}, \mathrm{D})$ suggesting antagonistic relationship between Wnt and VEGF/FGF pathways.

\section{Inhibition of budding and head regeneration by SU5416}

In order to examine if VEGF is involved in nervous system development, tube formation and/or branching, we treated hydra with SU5416 (Semaxanib), a potent and specific inhibitor of VEGF receptor tyrosine kinase 2 (Flk-1/KDR). Treatment of adult, non budding hydra with 5 and $10 \mu \mathrm{M}$ SU5416 for $48 \mathrm{~h}$ did not result in significant morphological changes, except for the blebbing at the end of the tentacles (Fig. 8A). On the other hand, treatment of budding hydra (adult polyps with stage 3 buds, Fig. 8B) with these concentrations of inhibitor for 24 and $48 \mathrm{~h}$ resulted in delay in elongation of bud in a dose-dependent manner (Fig. 8C, a-h). These results were not fully reversible since withdrawal of the inhibitor from the medium for 24 and $48 \mathrm{~h}$ could not result in normal elongation of the bud (Fig. 8C, i-p). This strongly indicates the involvement of VEGF in tube formation and/or branching in hydra. Similarly, in regeneration experiments, $48 \mathrm{~h}$ treatment of head and foot pieces of hydra after mid-gastric bisection resulted in delayed formation of tentacles (Fig. 9B). These effects were not reversible after 24 or $48 \mathrm{~h}$ since transferring $48 \mathrm{~h}$ treated pieces to fresh hydra medium did not result in normal emergence of tentacles (Fig. 9 C,D). On the other hand, inhibition of VEGF signalling by SU5416 did not affect foot regeneration (Fig. 9 A,c,d; 9 B,c,d).

\section{Discussion}

VEGF and FGF signalling pathways are known to play crucial roles in blood vessel formation and influence endothelial cells in a variety of ways. However, the identification of homologues of VEGF and FGF from invertebrates that lack endothelial cells or blood ves- 
A

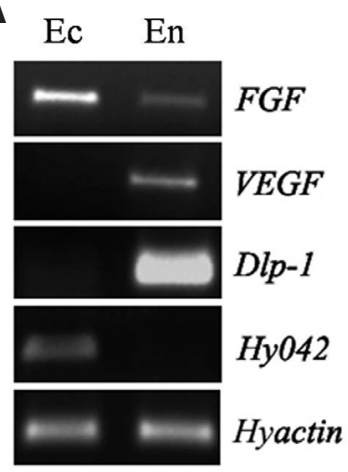

B

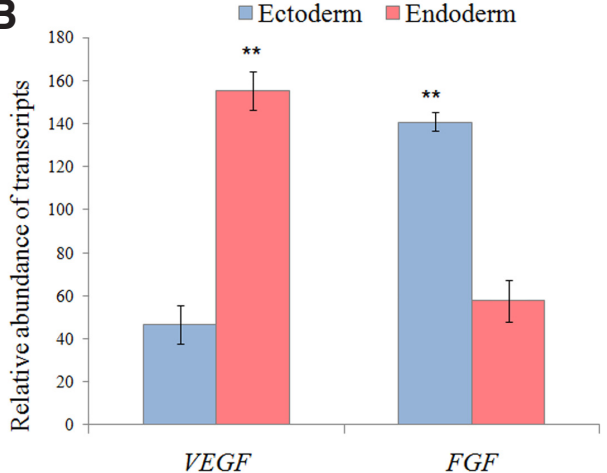

Fig. 6 (left). Tissue specific expression of VEGF and FGF in hydra. (A) Endodermal expression of VEGF and expression of FGF in both tissue layers is observed by RT-PCR. Clean separation of ectoderm (EC) and endoderm (En) was confirmed by the expression of Hy042 and Dlp1 in ectodermal and endodermal tissues respectively. (B) Histogram represents the relative abundance of transcripts of Hy042, DIp1, VEGF and FGF in ectoderm and endoderm. ${ }^{*}$ shows statistical significance, $p<0.001$. sels has led to re-inspection of basic functions of these signalling molecules.

VEGFs belong to VEGF/PDGF group of cysteine-knot superfamily, all the members of which are characterized by the presence of a signal peptide, VHD and conserved cysteine residues forming a typical cysteine-knot structure (reviewed in Holmes and Zachary 2005). In silico structural analysis of hydra VEGF amino acid sequence displays considerable conservation of signal peptide, VHD and cysteine knot suggesting structural conservation of VEGF from hydra to vertebrates. Data from various vertebrates reveal a high level of conservation of VEGF domain architecture across phyla. Hydra VEGF when compared with previously reported VEGFs showed high structural similarity to Orf virus VEGFE. VEGFE encoded by the Orf virus has been reported to be more useful for pro-angiogenic therapy because of its selective binding to VEGFR2 (Meyer 1999) and induction of mature blood vessels without causing oedema and inflammation in contrast to VEGFA (Shibuya 2009). We observe a close structural resemblance, with low RMSD, of hydra VEGF with VEGFE.

Similar to the VEGF pathway, FGF pathway is also conserved at both nucleotide and amino acid levels from early metazoans to higher vertebrates (reviewed in Itoh and Ornitz 2004). Though FGFs of varied sizes ( 17 to $34 \mathrm{kDa}$ ) have been identified, all members of this family share a conserved core region/FGF domain comprising of 120 amino acids that shows $30-60 \%$ sequence similarity (reviewed in Itoh and Ornitz 2004). Further, the presence of Glycine box, a characteristic feature found in all FGF family members, helps in communicating with the motifs of heparin-binding sites and in chemical bonding. It acts as a major determinant of the specificity of FGFs for HSPGs, provides stability and promotes their binding to cell surface FGFRs (Ashikari-Hada et al., 2004). In the present study, the presence of FGF domain and Glycine box was found in hydra FGF, thus demonstrating considerable structural conservation.

Fig. 7. Antagonism between Wnt and VEGF/FGF pathways. Formation of ectopic tentacles on the upper body column can be noticed in alsterpaullone treated live hydra (t) as compared to live control (c) (A). Expression analysis of VEGF and FGF with alsterpaullone treatment after 4 (B), 24 (C) and $48 \mathrm{~h}$ (D) by RT-PCR. Significant down-regulation of VEGF and FGF was observed with $5 \mu \mathrm{M}$ alsterpaullone after 24 (B) and $48 \mathrm{~h}$ (C). Control, DMSO and Alsterpaullone treatment represents lane numbers 1, 2 and 3 respectively. Histograms show the relative abundance of transcripts of VEGF and FGF after 4 and 24 and 48 h; significant up-regulation of Wnt was observed after $48 \mathrm{~h}$ with $5 \mu \mathrm{M}$ alsterpaullone treatment $(\mathbf{C}) .{ }^{*}$ and ${ }^{*} *$ shows statistical significance, $p<0.01$ and $p<0.001$. Scale bar, $500 \mu \mathrm{m}$.
A
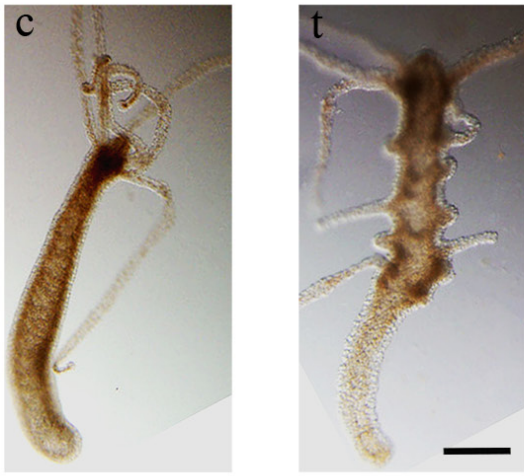

B

$4 \mathrm{~h}$

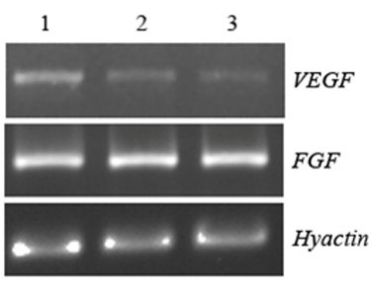

C

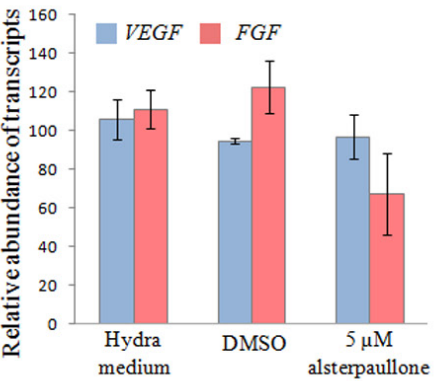

$24 \mathrm{~h}$

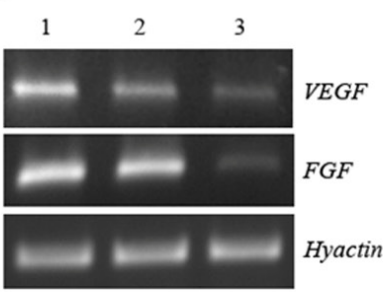

D

$48 \mathrm{~h}$

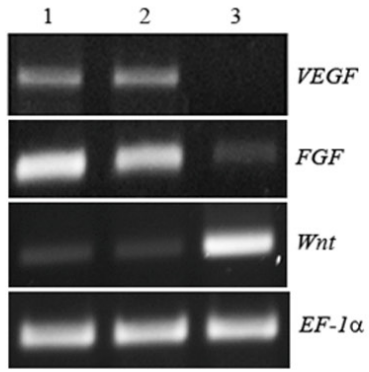

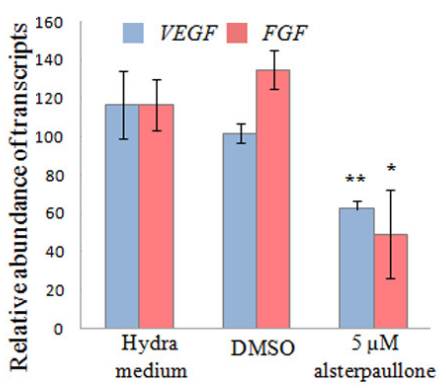

**

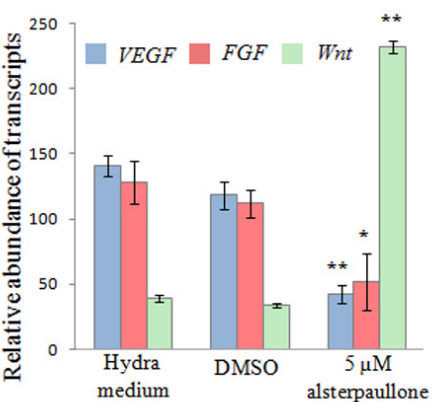


In situ hybridization and tissue specific PCR studies revealed the expression of VEGF in the endoderm and of $F G F$ in both ectoderm and endoderm. Though recent transcriptome-wide expression analysis has indicated that VEGF and FGF are predominantly expressed in ectodermal epithelial cells (Hemmrich et al., 2012), we consistently detect VEGF expression exclusively in the endodermal cells and FGF expression in both tissue layers. Previous reports showed the expression of FGFR (Kringelchen) during bud detachment (Sudhop et al., 2004). The localization of FGF, in the budding region of hydra thus suggests its possible role in interacting with FGFR. The possible function of VEGF in tube formation has already been shown in an anthozoan Cnidarian, $P$. carnea where it is expressed in the endoderm of tentacles and gastrovascular canal (Seipel et al., 2004). VEGF is well known for its involvement in key processes including cell migration and tube formation. Hence, localization of VEGF in the endoderm of tentacles suggests its possible involvement in tube formation, an ancestral function of VEGF signalling pathway. However, the expression pattern of $V E G F$ in the endoderm of $1 / 3^{\text {rd }}$ basal region in hydra coincides with reported expression of $C n N K-2$, a homologue of cardio-muscular tissue marker Nkx-2.5, in the peduncle (Grens et al., 1996). VEGF is known to induce $N k x 2.5$ in differentiated embryonic stem cells (Chen et al., 2006). Expression of both VEGF and $C n N K-2$ in the peduncle region of hydra thus suggests a possible crosstalk between VEGF and CnNK-2 pathways.

Localization of $F G F$ in the ectoderm of budding region by in situ hybridization suggested its possible presence in interstitial cells. We used a temperature sensitive strain, sf-1 of Hydra magnipapillata, which loses its interstitial cells after a heat shock at $28^{\circ} \mathrm{C}$ over time to confirm this. Expression of FGF was indeed down-regulated in heat-shocked sf-1 animals suggesting presence of FGF in l-cells. FGF-2 is known to be involved in maintaining stem cells in undifferentiated state (Zoumaro-Djayoon et al., 2011). Thus, localization of FGF in the ectoderm of budding region where large population of interstitial stem cells reside suggests its possible function in maintenance of interstitial stem cells. VEGFexpression was found to be up-regulated in heat-shocked sf-1 hydra. This was expected since total RNA used for RT-PCR from sf- 1 hydra at $28^{\circ} \mathrm{C}$ mainly contains RNA from endodermal cells (as I cells are destroyed), showing enhanced expression in heat-shocked animals further indicating that expression of VEGF in predominantly in the endodermal cells.

The finding that Wnt signalling affects VEGF and FGF pathways prompted us to study the expression pattern of VEGF and FGF in alsterpaullone-treated hydra. A crucial step in the canonical Wnt pathway is stabilization and accumulation of $\beta$-catenin in the nucleus as a consequence of GSK3 $\beta$ inhibition. Due to inactivation of GSK3 $\beta$ by alsterpaullone, Wnt pathway gets over-activated leading to formation of tentacles over the body column of hydra (Broun et al., 2005). Wnt and FGF signalling cascades have also been shown to interact both in a cooperative or an antagonistic manner, depending on the cell and tissue type (Mansukhani et al., 2005). Down-regulation of both VEGF and FGF with activated canonical Wnt signalling points towards antagonistic relationship between Wnt and VEGF/FGF signalling pathways.

VEGF has been implicated in nerve cell development, neuroprotection and nerve cell maintenance, in addition to tube formation, branching and cell migration. In an attempt to assess the functional role of VEGF in neural development and tube formation in hydra, we inhibited VEGF signalling in adult, non budding polyps, during bud formation and in regenerating hydra using SU5416. Treatment with SU5416 did not affect adult polyps but delayed elongation of buds in budding polyps and emergence of tentacles in regenerating hydra pieces. It is reported that the nerve cell density is increased during early development of a bud and the multipotent stem cells in the evaginating bud tissue proliferate and differentiate into neural cells (Berking, 1980). In view of this, inhibition of budding and elongation of tentacles due to reduced VEGF signalling suggests a role of VEGF in these processes.

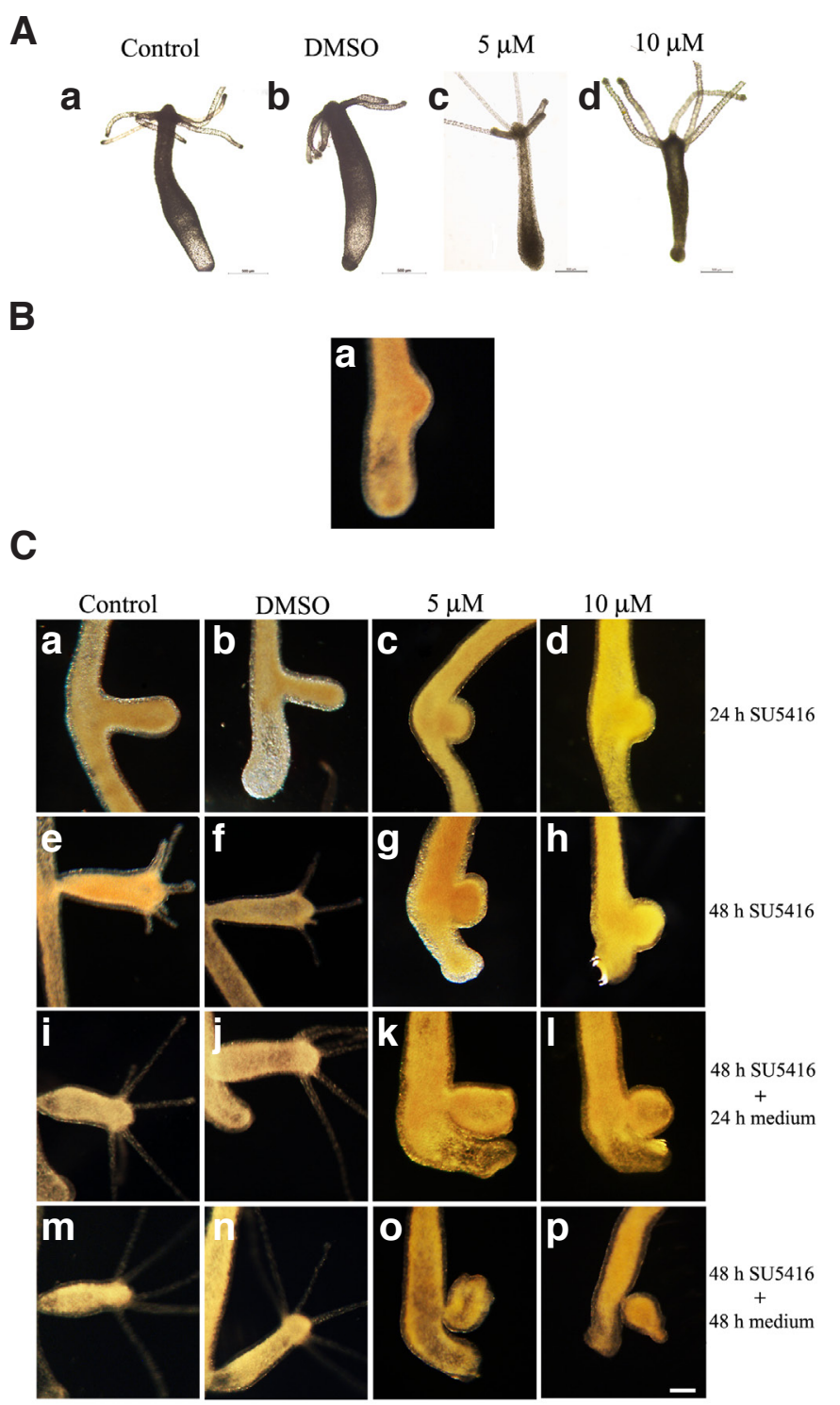

Fig. 8. Inhibition of elongation of bud by SU5416. Adult non budding polyps were treated with 5 or $10 \mu \mathrm{M}$ SU5416 for $48 \mathrm{~h}$. No significant change was observed in adult hydra with this treatment $(c, d)$ as compared to controls $(a, b)(\mathbf{A})$. When adult polyps with stage 3 buds (B), were treated with 5 and $10 \mu \mathrm{M}$ SU5416 for $24 \mathrm{~h}(\mathrm{c}, \mathrm{d})$ and $48 \mathrm{~h}(\mathrm{~g}, \mathrm{~h})$, a delay in the elongation of buds was observed as compared to the master controls $(a, e)$ and DMSO controls $(b, f)$. Normal elongation of the bud was not restored even after transferring the $48 \mathrm{~h}$ treated polyps to fresh normal hydra medium for further $24(k, 1)$ or $48 \mathrm{~h}(0, p)(\mathbf{C})$. Scale bars in (A, C), 500 and $100 \mu \mathrm{m}$, respectively. 


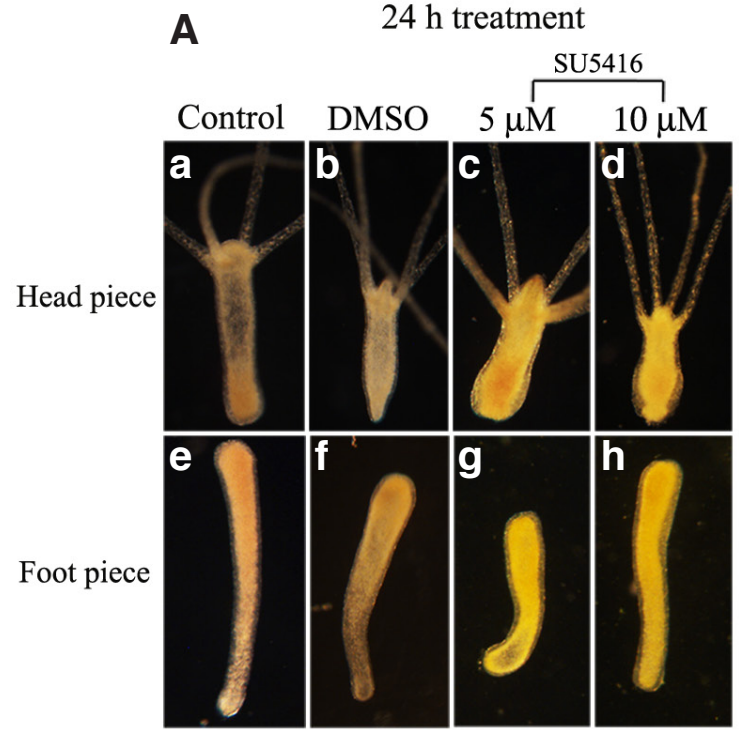

C $\quad 48 \mathrm{~h}$ treatment $+24 \mathrm{~h}$ medium

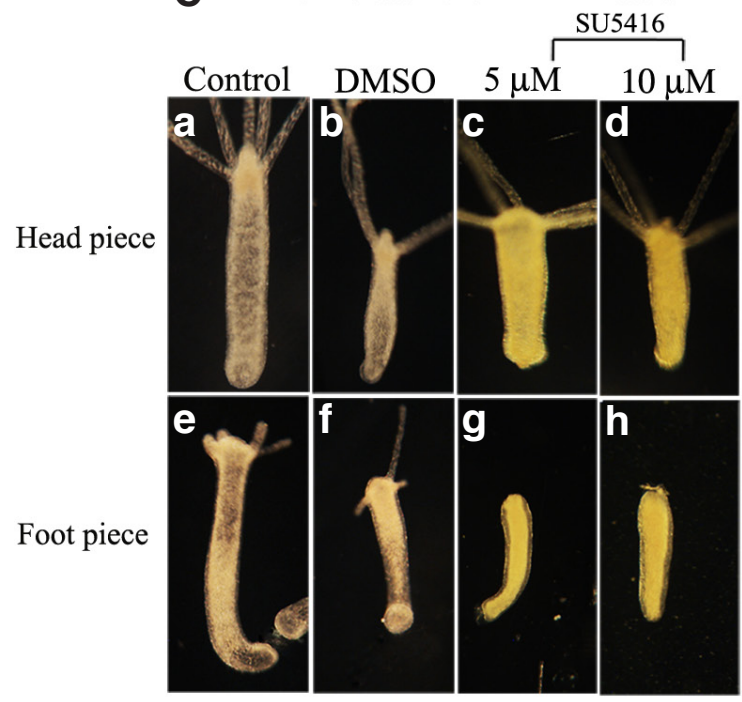

In conclusion, VEGF signalling is important in branching and nerve cell development and appears to have originated in the ancestral cell type giving rise to endodermal cells in Cnidaria, since the epithelio-muscular cells observed in Cnidarians are homologous to smooth muscle cells that cover blood vessels in higher vertebrates (reviewed in Muñoz-Chápuli 2011). Further, we speculate that FGF could be important in stem cell maintenance and also in neural development in hydra in accordance with its role in axon guidance and neural development in other invertebrates. Our findings on VEGF and FGF in hydra are significant since these could help in designing strategies for identifying the evolutionary ancient functions of these, and probably other growth factors.

\section{Materials and Methods}

\section{Hydra culture}

Clonal cultures of Hydra vulgaris Ind-Pune were maintained in hydra medium (Horibata et al., 2004) at a constant temperature of $18 \pm 1^{\circ} \mathrm{C}$ with $12 \mathrm{~h}$ light/dark cycle. The polyps were fed with freshly hatched Artemia salina nauplii on alternate days. sf- 1 hydra were kept for $8-10$ days at $28^{\circ} \mathrm{C}$
$48 \mathrm{~h}$ treatment
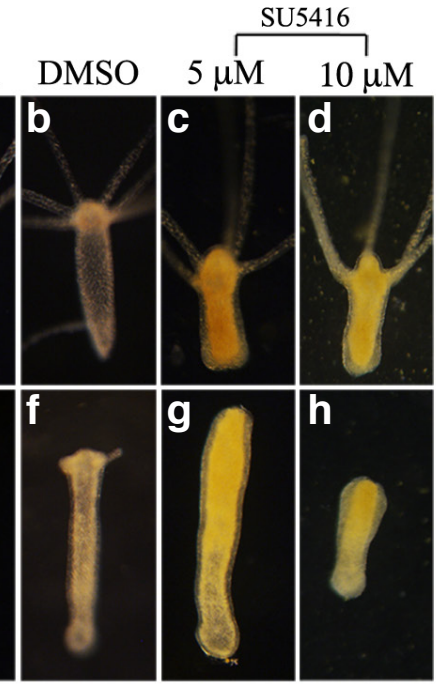

$48 \mathrm{~h}$ treatment $+48 \mathrm{~h}$ medium SU5416
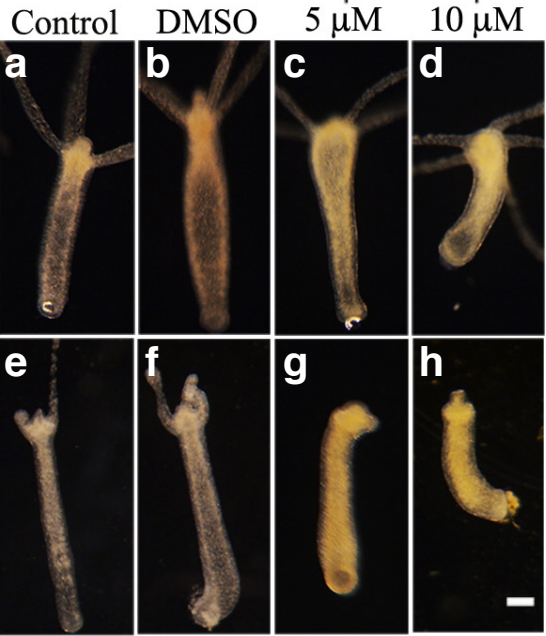

Fig. 9. Delay in head regeneration due to SU5416 treatment. Hydra polyps bisected at mid-gastric position were exposed to 5 and $10 \mu \mathrm{M}$ SU5416 for 24 (A) or 48 h (B). Control polyps regenerated both head $(e, f)$ and foot pieces $(a, b)$ within $48 \mathrm{~h}$, whereas head regeneration was delayed in 48 $h$ treated polyps $(g, h)(\mathbf{B})$. Transferring the $48 \mathrm{~h}$ treated hydra pieces to fresh medium did not restore head regeneration $(g, h)$ for $24 \mathrm{~h}(\mathbf{C})$, while signs of tentacle emergence of were seen ( $g, h$ ) after $48 h$ (D). Foot regeneration was not affected $(c, d)$ by 24 (A) or 48 h (B) SU5416 treatment. Scale bar, $100 \mu \mathrm{m}$.

to eliminate I-cells and control sf- 1 hydra were maintained at $18^{\circ} \mathrm{C}$ with 12 h light/dark cycle with alternate day feeding (Terada et al., 1998).

\section{Isolation and cloning of VEGF and} FGF homologues in hydra

The putative amino acid sequences for VEGF and FGF-2 from vertebrates and invertebrates were downloaded from the NCBI database. These sequences were compared with $H$ magnipapillata Genome database (http://hydrazome.metazome.net) for the presence of homologues using TBLASTX algorithm. Best scoring ESTs were chosen and used as queries for TBLASTX on the Genome browser to get contig (contiguous DNA sequence) maps. The amino acid sequences of VEGF and FGF were analyzed for conserved domains using SMART database. For cloning, total RNA extracted from hydra starved for $48 \mathrm{~h}$ was used to synthesize first strand cDNA. PCR reactions were carried out

using oligonucleotide primers corresponding to the predicted sequences of $H$. magnipapillata (VEGF: FW-GAAACACAAACTCACATACTTTCTATA, REV-ACTTCTGTTAAAAAAAATTTCAATCACCAT; FGF: FW-GTTTCTGACATACATCGATAATGGT, REV-TATCTTCGGATGCATAGTTGATCTT). The PCR conditions used were as follows: Initial denaturation at $94^{\circ} \mathrm{C}$ for $4 \mathrm{~min}$ followed by 35 cycles of denaturation at $94^{\circ} \mathrm{C}$ for $30 \mathrm{sec}$, annealing for $40 \mathrm{sec}$ at $59^{\circ} \mathrm{C}$ for VEGF and $60^{\circ} \mathrm{C}$ for FGF and extension at $72^{\circ} \mathrm{C}$ for $50 \mathrm{sec}$ and final extension at $72^{\circ} \mathrm{C}$ for $10 \mathrm{~min}$. The amplified PCR products were purified, cloned into pGEM-T Easy (Promega, Madison, WI, USA) and sequenced.

\section{Sequence analysis and comparison}

Comparison of VEGF protein sequences (Caenorhabditis elegans Pvf1, NM_065060.3; Danio rerio VEGFAa, BC162258.1; D. rerio VEGFAb, NM_001044855.2; Drosophila melanogaster Pvf1, NP_523407.1; D. melanogasterPvf2, NM_078775.2; D. melanogasterPvf3, NM_001103638.2; Gallus gallus VEGF, AB011078.1; Hydra vulgaris Ind-Pune VEGF, FJ767839.1; Mus musculus VEGF, M95200.1; Podocoryne carnea VEGF, AY508721; Xenopus laevis VEGF, NM_001097785.1; H. sapiens VEGFB, JX512460.1; M. musculus VEGFB, M_011697.3; D. rerio VEGFC, NM_205734.1; H. sapiens VEGFC, NM_005429.2; M. musculus VEGFC, NM_009506.2; D. rerio VEGFD, DQ402074.1; G. gallus VEGFD, 
EF569672.1; H. sapiens VEGFD, NM_004469.4; $M$. musculus VEGFD, NM_010216.1; Orf virus VEGFE, ABA00650) and FGF protein sequences (D. rerio FGF2, NM_212823; G. gallus FGF2, NM_205433; $H$. sapiens FGF2, NM_002006; $H$. vulgaris Ind-Pune FGF, JF803424.1; M. musculus FGF2, NM_008006; Nematostella vectensis FGFa1, DQ882655; N. vectensis FGF1B, EF068141; X. laevis FGF2, NM_001099871) was carried out by multiple sequence alignments generated using Clustal W (http:// www.ebi.ac.uk/clustalw/) to look for conserved regions. Homology based protein models were constructed using SPDBV database. Phylogenetic trees were constructed by NJ, ML and MP methods using MEGA5. Bootstrap analysis with 1000 replicates was carried out for each tree with random addition of sequences for 10 replicates.

\section{Whole mount in situ hybridization}

Whole-mount in situ hybridization using digoxygenin (DIG)- or biotinlabeled RNA probes was carried out as described by Martinez et al., (1997) with a few modifications. Briefly, the pGEM-T Easy vector harbouring either VEGF or FGF coding sequence (CDS) was linearized using Pst I and Apa I restriction enzymes followed by in vitro transcription. Sense or antisense probes were obtained using T7 or SP6 RNA polymerase and DIG-or Biotin-RNA labeling kits (Boehringer Mannheim).

Hydra polyps starved for $48 \mathrm{~h}$ were relaxed in $2 \%$ urethane for 2 min and fixed in $4 \%$ paraformaldehyde at $4 \mathrm{HC}$ overnight followed by repeated washes with 1 XPBS. Animals were permeabilized by proteinase $\mathrm{K}(10 \mu \mathrm{g} /$ $\mathrm{ml}$ ) at room temperature for $10 \mathrm{~min}$ followed by a wash with $1 \mathrm{X}$ Glycine in PBTw to stop proteinase K activity. Glycine was exchanged with $0.1 \mathrm{M}$ triethanolamine to reduce background staining for $5 \mathrm{~min}$ and hydra were refixed in $4 \%$ paraformaldehyde at $40 \mathrm{C}$ overnight. Subsequently, the animals were washed with PBTw and $2 X$ SSC, equilibrated in prehybridization buffer ( $50 \%$ formamide, $5 \mathrm{X}$ SSC, $0.02 \%$ tRNA, $0.1 \%$ CHAPS, $1 \mathrm{X}$ Denhardt's solution, $0.1 \%$ Tween 20 , heparin- $100 \mu \mathrm{g} / \mathrm{ml}$ and yeast tRNA$200 \mu \mathrm{g} / \mathrm{ml}$ ) for $2-3 \mathrm{~h}$ followed by hybridization for $36-60 \mathrm{~h}$ at $59^{\circ} \mathrm{C}$ (VEGF) and $60^{\circ} \mathrm{C}$ (FGF) in hybridization buffer (prehybridization buffer + labeled RNA probe). Probe concentrations for VEGF were approximately $27 \mathrm{pg} /$ $\mu \mathrm{l}$ for sense and $25 \mathrm{pg} / \mu \mathrm{l}$ for antisense and $F G F$ were $22 \mathrm{pg} / \mu \mathrm{l}$ for both sense and antisense probes. Hybridization using labeled sense probes was considered as controls. This was followed by stringency washes $(0.5 \mathrm{X}$ SSC $+0.1 \%$ CHAPS, $3 \times 20$ min each) and incubation with anti-digoxigenin or streptavidin antibody conjugated with alkaline phosphatase in a dilution of $1: 3000$ at $4^{\circ} \mathrm{C}$ overnight. Unbound antibody was washed with MABT (100 mM maleic acid, $150 \mathrm{mM} \mathrm{NaCl}, 0.1 \%$ Tween-20, $\mathrm{pH} 7.5,10 \times 20$ $\mathrm{min}$ ) at room temperature followed by equilibration with NTMT (100 mM $\mathrm{NaCl}, 100 \mathrm{mM}$ Tris- $\mathrm{HCl}, \mathrm{pH}$ 9.5, 50 mM MgCl, $2.1 \%$ Tween-20; 2×5 min) and NTMT containing $1 \mathrm{mM}$ levamisole $(1 \times 5 \mathrm{~min})$. Alkaline phosphatase staining was performed with Nitro Blue Tetrazolium/5-bromo-4-chloro3-indolyl-phosphate p-toluidine salt (NBT/BCIP) in NTMT. Following the color reaction, polyps were transferred to methanol.

\section{Histology}

Following in situ hybridization, hydra were rehydrated in methanol:PBTw grades and fixed in $4 \%$ paraformaldehyde overnight. Subsequently, hydra were washed several times with PBTw and dehydrated in graded series of ethanol, followed by washes with butanol $(3 \times 5 \mathrm{~min}), 1 \%$ celloidin in methyl salicylate $(2 \mathrm{~min})$ and chloroform $(2 \times 15 \mathrm{~min})$. Cold infiltration in chloroform-paraffin wax (1:1) for $90 \mathrm{~min}$ at $45^{\circ} \mathrm{C}$ and hot infiltration with paraffin wax at $60^{\circ} \mathrm{C}(2 \times 10 \mathrm{~min})$ were carried out. Hydra polyps were embedded individually in fresh molten wax at $60^{\circ} \mathrm{C}$. Blocks were prepared and sections of $10 \mu$ thickness were cut on a rotary retracting microtome. Sections were deparaffinized in xylene and mounted in DPX.

\section{Elimination of interstitial cell (I-cell) lineage}

A temperature sensitive mutant strain of Hydra magnipapillata, sf-1 were kept at $28^{\circ} \mathrm{C}$ for $8-10$ days to eliminate I-cells with alternate day feeding (Terada et al., 1988). sf- 1 hydra maintained at $18^{\circ} \mathrm{C}$ served as controls. Loss of I-cells was confirmed by macerating hydra in maceration medium (glycerol:glacial acetic acid:distilled water, 1:1:13) followed by microscopic examination. On confirming absence of I-cells, hydra from $28^{\circ} \mathrm{C}$ and $18^{\circ} \mathrm{C}$ were homogenized in Tri Reagent (Sigma, US) for total RNA extraction.

\section{RNA isolation and cDNA synthesis}

50-100 hydra polyps were homogenized in Tri reagent for total RNA extraction. After homogenization, chloroform $(200 \mu \mathrm{l})$ was added to the homogenate, mixed well for $15 \mathrm{sec}$ and allowed to stand for $2 \mathrm{~min}$ at $4^{\circ} \mathrm{C}$. The resultant mixture was centrifuged at $13000 \mathrm{rpm}$ for $15 \mathrm{~min}$ at $4 \mathrm{CC}$. Total RNA was precipitated from the aqueous phase using $500 \mu$ lisopropanol at $-20^{\circ} \mathrm{C}$ for $30 \mathrm{~min}$. The RNA pellet recovered after centrifugation was washed with $70 \%$ ethanol, air dried and dissolved in nuclease-free water. The integrity of RNA was checked on $1 \%$ formaldehyde agarose gel and quantified using a Nanodrop spectrophotometer. RNA $(\sim 1-2 \mu \mathrm{g})$ from control and test samples was used for preparation of CDNA using Improm II cDNA synthesis kit (Promega).

\section{Semi quantitative RT-PCR and statistical analysis}

Analysis of expression of desired genes was carried out by semi quantitative RT-PCR using cDNA as template. Each experiment was carried out in triplicate. Histograms were computed by normalizing the values of band intensities of test genes with Hyactin/EF1-a. Mean and standard deviation were calculated for each experimental set-up and statistical significance was calculated by Students paired t-test.

\section{Separation of ectoderm and endoderm}

Separation of ectoderm from endoderm was carried out by using procaine (Lange et al., 2011). Briefly, after cutting head and foot, the body columns were treated in solution $\mathrm{A}$ (equal volumes of $1 \%$ procaine$\mathrm{HCl}$ :dissociation medium [DM]:hydra medium [HM], $\mathrm{pH}-4.5)$ for 5-8 minutes, followed by treatment in solution $\mathrm{B}(1 \%$ procaine- $\mathrm{HCl}: \mathrm{DM}: \mathrm{HM}$, $\mathrm{pH}-2.5)$ for 3-5 minutes, both at $4^{\circ} \mathrm{C}$. The treated tissue was gently transferred to DM solution kept at room temperature. Once the ectodermal layer rolls into a ring like structure, it was teased apart with fine needles to separate it from the endoderm. Both the tissues were collected, homogenized in Tri Reagent and used for RNA extraction.

\section{Treatment with alsterpaullone}

Hydra starved for $24 \mathrm{~h}$ were treated with $5 \mu \mathrm{M}$ alsterpaullone for $24 \mathrm{~h}$ as described previously (Broun et al., 2005). Subsequently, hydra were repeatedly washed with hydra medium and transferred to fresh medium for up to $48 \mathrm{~h}$. Hydra polyps kept in dimethyl sulfoxide (DMSO) served as solvent controls while those in hydra medium served as master controls. For RNA extraction, the samples were homogenized in Tri Reagent after 4,24 and $48 \mathrm{~h}$ following transfer to fresh medium.

\section{SU5416 treatment}

Adult polyps and polyps with stage 3 buds were treated with 5 and 10 $\mu \mathrm{M}$ SU5416 (Calbiochem), a selective inhibitor of VEGF receptor tyrosine kinase, for $48 \mathrm{~h}$. The medium containing SU5416 was replenished after $24 \mathrm{~h}$. After $48 \mathrm{~h}$ treatment, the polyps were washed with hydra medium and transferred to fresh medium. Hydra treated with DMSO alone served as solvent controls while those in hydra medium were master controls. For regeneration studies, adult non budding hydra polyps were bisected at mid-gastric position and treated with the inhibitor for $48 \mathrm{~h}$. The treated pieces were transferred to fresh hydra medium and observed for a further $48 \mathrm{~h}$.

\section{Acknowledgements}

We thank Dr. Vidya Patwardhan and other members of our laboratory for discussions. We also thank the anonymous reviewer for excellent suggestions. KLS was a recipient of Junior and Senior Research Fellowships (NET) from Council of Scientific and Industrial Research, New Delhi. This work was funded by Agharkar Research Institute, Pune, India 
and Centre of Excellence in Epigenetics, Department of Biotechnology, Government of India.

\section{References}

ASHIKARI-HADA S, HABUCHI H, KARIYA Y, ITOH N, REDDI AH, KIMATA K (2004). Characterization of growth factor-binding structures in heparin/heparan sulfate using an octasaccharide library. J Biol Chem 279: 12346-12354.

BERKING S (1980). Commitment of stem cells to nerve cells and migration of nerve cell precursors in preparatory bud development in Hydra. Embryol exp Morph 60: 373-387.

BODE HR (1996). The interstitial cell lineage of hydra: a stem cell system that arose early in evolution. J Cell Sci 109: 1155-1164.

BORGAVE S, GHASKADBI S (2009). Fibroblast growth factor regulates early mesoderm and neural development in chick embryo through its action on brachyury, goosecoid, ERNI and noggin. Curr Sci 96: 1217-1223.

BÖTTGER A, STRASSER D, ALEXANDROVA O, LEVIN A, FISCHER S, LAS M, RUDD S, DAVID CN (2006). Genetic screen for signal peptides in Hydra reveals novel secreted proteins and evidence for non-classical protein secretion. Eur J Cell Biol 85: 1107-1117.

BROUN M, GEE L, REINHARDT B, BODE HR (2005). Formation of the head organizer in hydra involves the canonical Wnt pathway. Development 132: 2907-2916.

CHANDRAMORE K, ITO Y, TAKAHASHI S, ASASHIMA M, GHASKADBI S (2010). Cloning of noggin gene from hydra and analysis of its functional conservation using Xenopus laevis embryos. Evol Dev 12: 267-274.

CHEN Y, AMENDE I, HAMPTON TG, YANG Y, KE Q, MIN JY, XIAO YF, MORGAN JP (2006). Vascular endothelial growth factor promotes cardiomyocyte differentiation of embryonic stem cells. Am J Physiol Heart Circ Physiol 29: H1653-H1658.

GRENSA, GEE L, FISHER DA, BODE HR (1996). CnNK-2, an NK-2 homeobox gene, has a role in patterning the basal end of the axis in hydra. Dev Biol 180: 473-488.

HEMMRICH G, KHALTURIN K, BOEHM AM, PUCHERT M, ANTON-ERXLEBEN F, WITTLIEB J, KLOSTERMEIER UC, ROSENSTIEL P, OBERG HH, DOMAZETLOSO T, SUGIMOTO T, NIWA H, BOSCH TC (2012). Molecular signatures of the three stem cell lineages in Hydra and the emergence of stem cell function at the base of multicellularity. Mol Biol Evol 29: 3267-3280.

HOLMES DI, ZACHARY I (2005). The vascular endothelial growth factor (VEGF) family: angiogenic factors in health and disease. Genome Biol 6: 209.

HORIBATA Y, SAKAGUCHI K, OKINO N, IIDA H, INAGAKI M, FUGISAWA T (2004). Unique catabolic pathway of glycosphingolipids in a hydrozoan, Hydra magnipapillata, involving endoglycoceramidase. J Biol Chem 279: 33379-33389.

ITOH N, ORNITZ DM (2004). Evolution of Fgf and Fgfr gene families. Trends Genet 20: 563-569.

JIN K, ZHUY, SUN Y, MAO XO, XIE L, GREENBERG DA (2002). Vascular endothelial growth factor (VEGF) stimulates neurogenesis in vitro and in vivo. Proc Natl Acad Sci USA 99: 11946-11950.

KHOT S, GHASKADBI S (2001). FGF signaling is essential for the early events in the development of the chick nervous system and mesoderm. Int JDev Bio/45:877-885

LANGE C, HEMMRICH G, KLOSTERMEIER UC, LÓPEZ-QUINTERO JA, MILLER DJ, RAHN T, WEISS Y, BOSCH TC, ROSENSTIEL P (2011). Defining the origins of the NOD-like receptor system at the base of animal evolution. Mol Biol Evol 28: 1687-1702.

LI W, KOHARA H, UCHIDA Y, JAMES JM, SONEJI K, CRONSHAW DG, ZOU YR, NAGASAWA T, MUKOUYAMA YS (2013). Peripheral Nerve-Derived CXCL12 and VEGF-A Regulate the Patterning of Arterial Vessel Branching in Developing Limb Skin. Dev Cell 24: 359-371.

MANSUKHANIA, AMBROSETTID, HOLMESG, CORNIVELLIL, BASILICOC (2005) Sox2 induction by FGF and FGFR2 activating mutations inhibits Wnt signaling and osteoblast differentiation. J Cell Bio 168: 1065-1076.

MARTINEZD, DIRKSEN M, BODE PM, JAMRICH M, STEELE RE, BODE HR (1997). Budhead, a fork head/HNF-3 homologue, is expressed during axis formation and head specification in Hydra. Dev Biol 192: 523-536.

MATUS DQ, THOMSEN GH, MARTINDALE MQ (2007). FGF signaling in gastrulation and neural development in Nematostella vectensis, an anthozoan cnidarian. Dev Genes Evol 217: 137-148.

MEYERM, CLAUSSM, LEPPLE-WIENHUESA, WALTENBERGERJ,AUGUSTINHG ZICHE M, LANZ C, BÜTTNER M, RZIHA HJ, DEHIO C (1999). A novel vascular endothelial growth factor encoded by Orf virus, VEGF-E, mediates angiogenesis via signalling through VEGFR-2 (KDR) but not VEGFR-1 (FIt-1) receptor tyrosine kinases. EMBO J 18: 363-374

MOCHIZUKI K, HIROKO S, KOBAYASHI S, FUJISAWA C, FUJISAWA T (2000) Expression and evolutionary conservation of nanos-related genes in Hydra. Dev Genes Evol 210: 591-602.

MUÑOZ-CHÁPULI R (2011). Evolution of angiogenesis. Int J Dev Biol 55: 345-351 REDDY PC, BARVE A, GHASKADBI S (2011). Description and phylogenetic characterization of common hydra from India. Curr Sci 101: 736-738.

RUIZ DE ALMODOVAR C, LAMBRECHTS D, MAZZONE M, CARMELIET P (2009) Role and therapeutic potential of VEGF in the nervous system. Physiol Rev 89 : 607-648.

SEIPEL K, EBERHARDT M, MÜLLER P, PESCIA E, YANZE N, SCHMID V (2004) Homologs of vascular endothelial growth factor and receptor, vegf and vegfr, in the jellyfish Podocoryne carnea. Dev Dyn 231: 303-312.

SHIBUYAM (2009). Unique signal transduction of the VEGF family members VEGF-A and VEGF-E. Biochem Soc Trans 37: 1161-1166.

SUDHOP S, COULIER F, BIELLERA, VOGTA, HOTZT, HASSELM (2004). Signalling by the FGFR-like tyrosine kinase, Kringelchen, is essential for bud detachment in Hydra vulgaris. Development 131: 4001-4011.

TERADA H, SUGIYAMA T, SHIGENAKA Y (1988). Genetic analysis of developmental mechanisms in hydra. XVIII. Mechanism for elimination of the interstitial cell lineage in the mutant strain Sf-1. Dev Biol 126: 263-269.

ZOUMARO-DJAYOON AD, DING V, FOONG LY, CHOO A, HECK AJ, MUÑOZ J (2011). Investigating the role of FGF-2 in stem cell maintenance by global phosphoproteomics profiling. Proteomics 11: 3962-3971. 


\section{Further Related Reading, published previously in the Int. J. Dev. Biol.}

Hydra, a fruitful model system for 270 years

Brigitte Galliot

Int. J. Dev. Biol. (2012) 56: 411-423

http://dx.doi.org/10.1387/ijdb.120086bg

Modeling pattern formation in hydra: a route to understanding essential steps in development

Hans Meinhardt

Int. J. Dev. Biol. (2012) 56: 447-462

http://dx.doi.org/10.1387/ijdb.113483hm

Hydra, the everlasting embryo, confronts aging

Daniel E. Martínez and Diane Bridge

Int. J. Dev. Biol. (2012) 56: 479-487

http://dx.doi.org/10.1387/ijdb.113461dm

Hydra, a model system to trace the emergence of boundaries in developing eumetazoans Angelika Böttger and Monika Hassel

Int. J. Dev. Biol. (2012) 56: 583-591

http://dx.doi.org/10.1387/ijdb.113454ab

Cnidarians as a model system for understanding evolution and regeneration Brigitte Galliot and Volker Schmid

Int. J. Dev. Biol. (2002) 46: 39-48

http://dx.doi.org/10.1387/ijdb.11902686

5 yr ISI Impact Factor $(2011)=2.959$
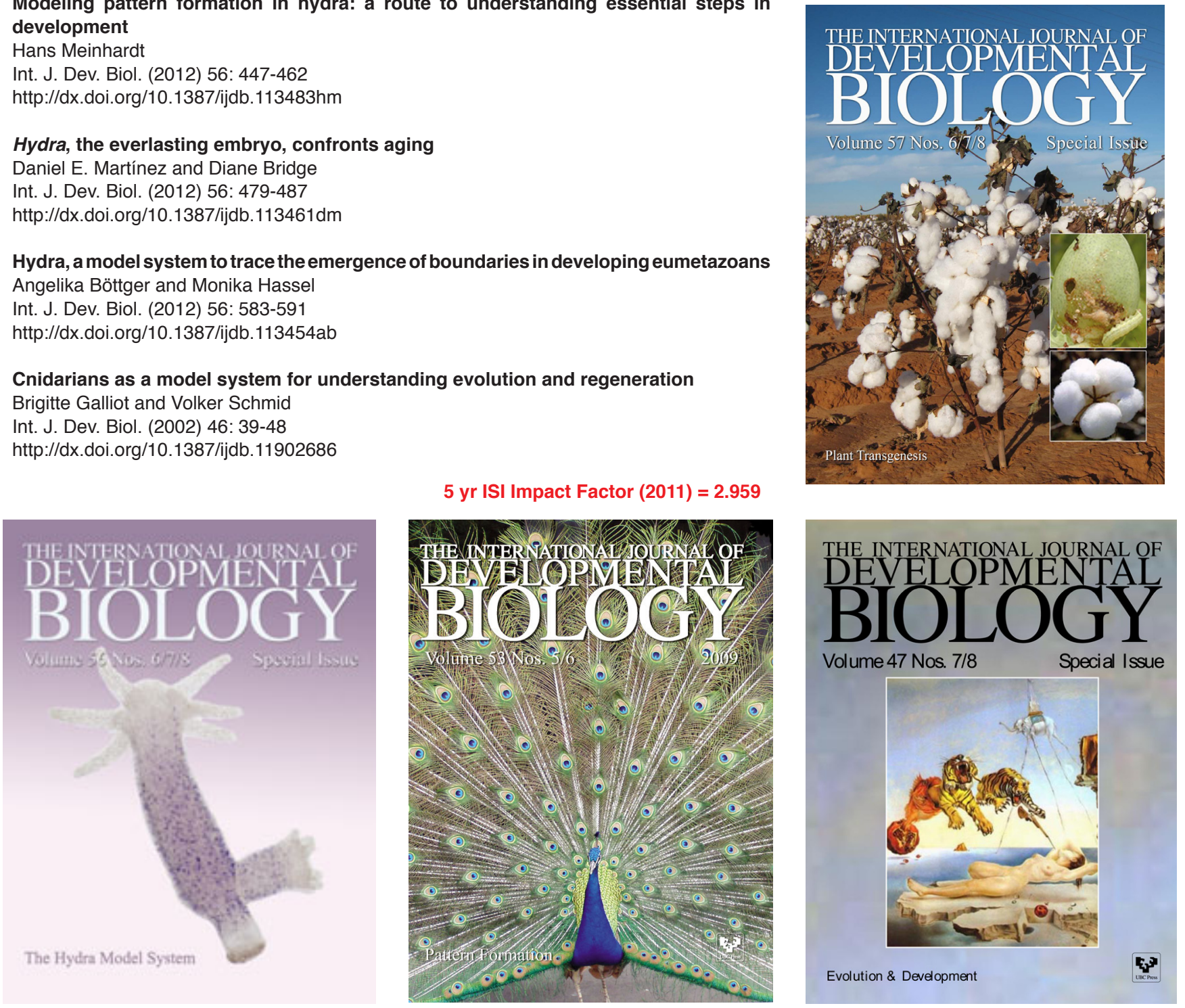

Volume 47 Nos. $7 / 8$

Special Issue

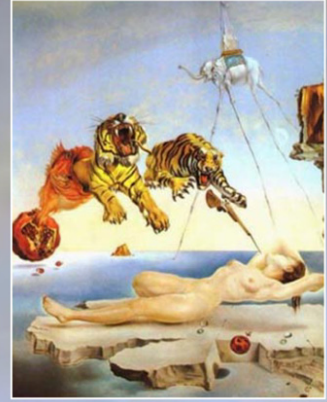

Evolution \& Development 